\title{
Urban climate change mitigation and adaptation planning: Are Italian cities ready?
}

\author{
Filomena Pietrapertosa ${ }^{\mathrm{a}, *}$, Monica Salvia ${ }^{\mathrm{a}}$, Sonia De Gregorio Hurtado ${ }^{\mathrm{b}}$, Valentina D'Alonzo ${ }^{\mathrm{c}, \mathrm{d}}$, \\ Jon Marco Church ${ }^{\mathrm{e}}$, Davide Geneletti ${ }^{\mathrm{c}}$, Francesco Musco ${ }^{\mathrm{f}}$, Diana Reckien ${ }^{\mathrm{g}}$ \\ a Institute of Methodologies for Environmental Analysis (IMAA), National Research Council of Italy (CNR), C. da S. Loja, 85050 Tito Scalo, PZ, Italy \\ ${ }^{\mathrm{b}}$ Department of Urban and Spatial Planning, School of Architecture, Universidad Politécnica de Madrid, Av. Juan de Herrera 4, 28040 Madrid, Spain \\ ${ }^{\mathrm{c}}$ Department of Civil, Environmental and Mechanical Engineering, University of Trento, Via Mesiano 77, 38123 Trento, Italy \\ ${ }^{\mathrm{d}}$ Institute for Renewable Energy, Eurac Research, Via A. Volta 13/A, 39100 Bolzano, Italy \\ ${ }^{\mathrm{e}}$ EA 2076 HABITER, University of Reims, BP 30, 57 Rue Pierre Taittinger, 51571 Reims Cedex, France \\ ${ }^{\mathrm{f}}$ Department of Design and Planning in Complex Environments, University IUAV of Venice, Ca' Tron, Santa Croce 1957, 30135 Venice, Italy \\ ${ }^{\mathrm{g}}$ Faculty of Geo-Information Science and Earth Observation (ITC), University of Twente, PO Box 217, 7500 AE, Enschede, the Netherlands
}

\section{A B S T R A C T}

Climate Action Planning is one of the top priorities of cities in order to reduce greenhouse gas emissions and strengthening climate-resilience, as pointed out by the New Urban Agenda and the Paris Agreement.

This study aims at assessing the development of climate change mitigation and adaptation planning in Italian cities. To this end, we analysed the availability of Local Climate Plans (LCPs) in 76 cities, which are included in the Eurostat Urban Audit (UA-2015) database. In a further step, we analysed the content of the urban climate change mitigation and adaptation plans available in a smaller sample of 32 Italian cities of 2007 Eurostat Urban Audit database (UA-3), looking at the single actions undertaken for addressing mitigation and adaptation to climate change. Results show the almost total absence of comprehensive and stand-alone urban climate change adaptation plans in Italy (except for two cities, Ancona and Bologna), whereas we found that in 61 out of 76 cities municipal civil protection plans are the instruments that deal with local emergencies associated to extreme weather events. On the other hand, 56 out of 76 urban climate change mitigation plans (i.e. Sustainable Energy Action Plans) are being developed in the framework of the Covenant of Mayors, which is a transnational network of local governments created by the European Union (EU) in 2012. The results obtained on the mitigation side point out that, in absence of a national law that imposes Italian cities to develop LCPs, transnational networks are an effective boost to voluntary commitment to reach EU climate and energy objectives.

\section{Introduction}

Cities are places of high overall primary energy consumption and high GHG emissions (Sims et al., 2007). Moreover, the growing urbanization and the complex patterns of urban economic assets, infrastructure and services make cities also particularly vulnerable to climate change (Geneletti \& Zardo, 2016; IPCC, 2012). Hence, improving climate mitigation and adaptation strategies in urban areas is crucial for sustainable development, a role that cities increasingly take on (Rosenzweig, Solecki, Hammer, \& Mehrotra, 2010; Van Staden \& Musco, 2010) and that is acknowledged by international organizations supporting their efforts (ICLEI, 2010).

Among multiple possible pathways, climate planning at the local level is a key avenue to mainstream mitigation and adaptation actions (Measham et al., 2011). Cities are the ideal framework for implementing low-carbon policies (Gouldson et al., 2015) and adaptation strategies through a strategic planning process shared with citizens and local stakeholders (Geels, 2011). In the words of Picketts, Déry, and Curry (2013), climate adaptation planning "is well suited to local levels of governments, as citizens can participate in creating targeted adaptation strategies that address the important regional impacts, and these strategies will provide tangible benefits to local residents". As shown by reviews of planning documents undertaken for European cities (Reckien et al., 2014; Reckien et al., 2014; Reckien, Flacke, Olazabal, \& Heidrich, 2015), the UK (Heidrich, Dawson, \& Reckien, 2013), Italy and Spain (De Gregorio Hurtado et al., 2015), Australia (Baker, Peterson, Brown, \& McAlpine, 2012) and North America (Zimmerman \& Faris, 2011), urban planning has increasingly been addressing climate mitigation and adaptation issues (Kumar \& Geneletti, 2015).

Regarding the content of Local Climate Plans (LCPs), for example,

\footnotetext{
* Corresponding author.

E-mail addresses: filomena.pietrapertosa@imaa.cnr.it (F. Pietrapertosa), monica.salvia@imaa.cnr.it (M. Salvia), sonia.degregorio@upm.es (S. De Gregorio Hurtado), valentina.dalonzo@unitn.it, valentina.dalonzo@eurac.edu (V. D'Alonzo),

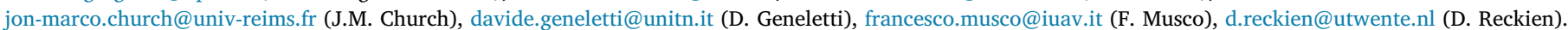


the study by Reckien, Flacke, Dawson, et al. (2014) identified that: (i) adaptation plans are far fewer than mitigation plans in European cities, i.e. about $30 \%$ as compared to $65 \%$, respectively; (ii) a profound NorthSouth gradient with fewer plans in the South, except for smaller cities; and (iii) a cumulative $\mathrm{CO}_{2} /$ GHG-reduction target of about $37 \%$. Moreover, the study pointed out that mitigation measures concentrated mostly on energy saving, energy efficiency and renewables, thus focusing only on the energy sector. On the other hand, adaptation plans were found to be broader in their scope and rather vague dealing, for instance, with urban planning and management, water management, awareness raising, etc. Concrete measures were seldom mentioned. Also, Baker et al. (2012, p. 127) summarize for Australia that "local governments were not effectively planning for climate impacts. While they were aware of expected climate change impacts, their capacity to use this information to develop geographically specific action plans was limited." The lack of LCPs is often connected to a lack of resources and capacity of local governments to tend to climate planning (Reckien et al., 2015). It is also related to multi-level governance systems in which the upper levels of government do not set policy frameworks that encourage and guide local climate action (De Gregorio Hurtado et al., 2014), which is particularly important in the case of medium and small cities. To overcome the lack of policy references and resources, many European cities use the services of climate-related national or transnational networks of local authorities, particularly when national and regional guidelines and support are absent. This is the situation in many Southern and Eastern European countries and cities (Pietrapertosa, Khokhlov, Salvia, \& Cosmi, 2018; Reckien, Flacke, De Gregorio Hurtado, et al., 2014). Climate networks are highly important also, for example, for cities in the United States (Zimmerman \& Faris, 2011).

The cited literature notes that, despite the diffusion of local climate planning, it is still necessary to pay increased attention to adaptation at the local level (Baker et al., 2012), particularly to cities in vulnerable locations (along rivers, coasts) and without resources (adaptive capacity, high unemployment) (Reckien et al., 2015).

As pointed out by the Intergovernmental Panel on Climate Change (IPCC) the Mediterranean basin is one of the main climate change hotspot, that is, one of the most responsive areas to climate change. In this region, Italian cities are particularly vulnerable to climate change and are already experiencing a rise in temperatures and increases in water scarcity, frequency of floods, forest fires, windstorms and storm surges. A dossier of Legambiente, the largest environmental association in Italy (Legambiente, 2018) shows that 198 Italian municipalities have been affected by negative impacts of climate change, from 2010 to 2018, recording 340 extreme weather events, 109 cases of infrastructure damaged from heavy rainfall, and 157 people victims of bad weather.

This study aims at contributing to the mentioned studies by analysing urban climate actions in Italy, focusing at how these vulnerabilities are dealt with in Italian cities through the content analysis of LCPs of a well-distributed and balanced sample of cities from the Urban Audit database of Eurostat (Eurostat, 2007; Eurostat, 2015). We refer to LCPs as a general term that includes all forms of planning undertaken at city level that contain policies that are relevant for climate change mitigation and adaptation. This general term is used because: (i) some aspects of spatial planning in Italy are regulated at the regional level, hence different regions may adopt different terminology and require different content for their planning instruments; (ii) climate adaptation/mitigation-relevant content can be found in the country also in urban planning instruments or in documents that focus on issues different from, or broader than climate change (e.g., civil defence and emergency plans).

To our knowledge, this is the second study of this kind in Italy, only preceded by one that can be considered as the research background of this study, conducted on a smaller sample of plans (UA-3 from Eurostat, 2007) and with a simplified review framework than the one proposed here (De Gregorio Hurtado et al., 2015). This first study revealed some dynamism in LCPs, such as identification of ambitious emission reduction targets; holistic approaches to mitigation strategies; it also found shortcomings in the information baseline and implementation measures of proposed strategies. There is also a report to share the experience of Italy at the international level, which uses an even smaller subset of cities, looks for good practices and focuses more on the competences of local authorities (Church, 2013). This study points out the high level of decentralization of climate planning despite responsibility that is still with the central government, as well as the great variety of measures, where research, innovation and competitiveness often play an important role.

The purpose of this paper is to make steps forward in the assessment of the development of local climate planning in Italy, to identify and discuss the main shortcomings of the plans related to the implementation of plans and measures, Italy's climate goals, and international agreements, and propose recommendations for the improvement of the plans and the policy framework in which the plans are developed. Particularly, our analysis addresses the following main research questions:

- How Italian cities are aware of impacts of climate change and how they are acting?

- How ambitious are the mitigation policies of cities?

- What cities are doing to cope with their climate vulnerabilities?

- What mitigation and adaptation topics and instruments (with associated actors and funding mechanisms) are contained in LCP?

Section 2 provides an overview of the Italian context related to mitigation and adaptation planning. Section 3 describes our methods for selecting the sample of cities and identifying the relevant LCPs. It also presents the review protocol that was used to analyse the content of the plans. Our results are illustrated and discussed in Section 4. Finally, some conclusions and recommendations are presented in Section 5.

\section{The Italian National Framework on mitigation and adaptation}

In compliance with the 1997 Kyoto Protocol, the Italian Ministry for the Environment, Land and Sea (IMELS) supported the development and implementation of the 2002 National Action Plan to reduce GHGs and is currently preparing a new National Plan for Energy and Climate, consistently with the Paris Agreement. At the same time, the Ministry of Economic Development released the Italian National Energy Strategy (SEN) (MISE, 2017), which aims at achieving and exceeding the environmental and decarbonisation targets established by the $2008 \mathrm{Cli}$ mate and Energy Package ("20-20-20" package) of the European Union and take on a leading role in defining and implementing the Roadmap 2050. In particular, according to the SEN, Italy intends to reduce GHG emissions of $39 \%$ by 2030 and $63 \%$ by 2050 respect to 1990 levels.

Concerning adaptation, the National Strategy for Adaptation to Climate Change (IMELS, 2014) was approved in October 2014, although several sectoral strategic documents have already included climate change adaptation aspects (e.g., National Biodiversity Strategy, White Paper on Challenges and Opportunities for Rural Development to Mitigate and Adapt to Climate Change). The National Strategy for Adaptation to Climate Change (IMELS, 2014) provides an overview of the impacts of climate change in several socio-economic sectors and natural systems, identifying a set of actions and adaptation measures to address these impacts. The portfolio of actions and measures selected have to be carefully evaluated and selected through appropriate criteria in the National Adaptation Plan to Climate Change which is, in accordance with the EEA definition, "a more detailed document providing a roadmap for the implementation of specific adaptation actions that are being planned" (EEA, 2013, p. 68).

The Italian National Adaptation Plan to Climate Change is currently administered by the IMELS that, in October 2017, closed a public 
consultation aiming at collecting comments and integrations from institutional stakeholders, but it hasn't be approved so far. In particular, a comprehensive questionnaire was set to investigate the perceptions of impacts and vulnerabilities and to collect actions to cope with climate change and a wide public consultation on the first draft was carried out involving citizens, associations and stakeholders.

The processes to define the Strategy and the Plan have been quite different. In the case of the Strategy, a wide process of collaborative involvement of scientific communities of different disciplines has been organised both in the definition and in the process of reviewing. In the case of the Plan the process of consultation followed a more oriented 'top down' approach, involving sectoral scientific communities only after the publication of a first plan proposal. Looking in particular at the sections dedicated to urban environments, the range of actions proposed in the Plan reveal a disconnection with local and regional planning systems - in all cases - as they do not include potential implications with the legal framework of regional planning, that in Italy represents the main asset for local and urban governance. The Plan risks being impossible to implement, because of lack of technical tools to integrate actions in ordinary planning processes. It is therefore necessary to focus on the urban level to understand the role of Italian cities in the framework of the national climate policies, as outlined by Heidrich et al. (2016).

\subsection{Focus on the urban level}

The current Italian legislation lacks National laws binding municipalities to develop any kind of plan or strategy aimed at reducing greenhouse gases or adapting cities to climate change. An exception is provided by the Municipal Energy Plan (Piano Energetico Comunale PEC), introduced by the 1991 national Law (Italian Law 10/1991, art. 5) for cities with more than 50,000 citizens, and the Urban Plan for Sustainable Mobility (Piano Urbano della Mobilità Sostenibile - PUMS), more recently introduced by a national Decree from the Ministry of Infrastructure and Transport (Decree n. 257, art. 3, 2016) for municipalities and associations thereof with more than 100,000 inhabitants. Thus, on the one hand, larger cities have developed, and sometimes upgraded, their Municipal Energy Plan, aimed at identifying the current energy balance and programming energy saving and renewable energy interventions, with positive repercussions on the reduction of GHG emission. On the other hand, the newly introduced Urban Plan for Sustainable Mobility will allow cities to take action on sustainable mobility with a medium to long-term (10-year) horizon, but with predefined time-based verifications and monitoring, promoting participation and coordinating with sectoral and urban planning on a supra-scale and communal scale.

This confirms that cities have assumed an increasingly important role, moved originally by their interest to plan their future in line with sustainability criteria (De Gregorio Hurtado et al., 2014).

In 2008, a new urban initiative launched by the European Union caught the interest of many Italian cities: the Covenant of Mayors (CoM). This network was established after the adoption of the 2020 European Union Climate and Energy Package to endorse and support the efforts deployed by local authorities in the implementation of sustainable energy policies. The CoM has had a big echo among Italian mayors, reaching the highest number of signatory cities in Europe. As a result, many Sustainable Energy Action Plans (SEAPs) have been developed in Italy, formalizing the political commitment of Mayors to curb GHG emissions on their territory by at least $20 \%$ by 2020 .

As concerns adaptation, the Covenant of Mayors Initiative on Climate Change Adaptation (Mayors Adapt), launched in 2013 in the framework of the EU Adaptation Strategy, was merged with the Covenant of Mayors and from 2017 onwards was entirely integrated into the new Covenant of Mayors for Climate and Energy which "pledge to reduce $\mathrm{CO}_{2}$ emissions by at least $40 \%$ by 2030 and to adopt an integrated approach to tackling mitigation and adaptation to climate change" (Covenant of Mayors for Climate and Energy, 2017). Signatories of the new Covenant of Mayors for Climate and Energy now commit to prepare and implement Sustainable Energy and Climate Action Plans (SECAP). Recently, Covenant of Mayors for Climate and Energy, 2018 and the Compact of Mayors (2017), another city network addressing climate change launched at the 2014 United Nations Climate Summit in New York, have come together to form the Global Covenant of Mayors for Climate \& Energy, aiming at combining efforts and leadership to accelerate climate action at the local level worldwide (EC, 2016).

\section{Methodology}

Following the methodological approach utilized in the EU-28 analysis (Reckien et al., 2018), two main issues were widely debated at the beginning of the study in order to setup the methodological approach and to fully address our research questions concerning the assessment of local climate planning in Italy. First, which Local Climate Plans (LCPs) needed to be investigated in our case study and, second, which cities could be included in the Italian sample.

An exhaustive description of how these two issues were addressed in our study is reported in the following sections.

\subsection{The LCPs under focus}

In Italy, there is no national legal requirement to adopt Local Climate Plans, as stand-alone documents. In this study, we investigated the availability of planning documents or strategies focusing on mitigation $(\mathrm{M})$, adaptation (A) or addressing mitigation and adaptation together $(\mathrm{M} / \mathrm{A})$.

To prioritize all these planning documents in order of strategic importance we introduced a three-level analysis framework based on (Reckien et al., 2018). As depicted in Fig. 1, we started our analysis searching comprehensive and stand-alone plans (Level 1). Then, we assessed whether they had been developed autonomously (Level 1-A) or had been induced by international urban climate networks (Level 1-B). For those cities without comprehensive plans, we also investigated the availability of sectoral plans addressing single aspects of climate change in stand-alone documents (Level 2) and, in their absence, on climaterelated local-level plans (Level 3).

In particular, this approach was based on the following definitions.

Comprehensive and stand-alone (Level 1): In this category, we included stand-alone documents relevant for the entire urban area and that at least mention 'climate' or 'climate change' in the title or as a main motivation of the plan development in the introduction. We introduced a further distinction with regard to the framework in which they were developed:

- Autonomously developed (Level 1-A): Adaptation/mitigation plans developed by a local government, independently from international networks or international funding;

- Internationally induced (Level 1-B): Plans that were developed within international urban climate networks, such as the Covenant of Mayors and the Compact of Mayors (e.g. SEAPs).

Sectoral (Level 2): In absence of mitigation and adaptation plans/ strategies developed for the entire city, we checked for sectoral plans with a climate dimension, addressing single aspects of climate change in stand-alone documents, relating to particular sectors (energy, heat wave, flooding, etc.). Only sectoral plans with at least a major section on 'climate' or 'climate change' were included in this category.

Related to Climate Change (Level 3): For cities lacking Level 1 and Level $2 \mathrm{M} / \mathrm{A}$ plans, we looked at local plans that are relevant from a climate perspective (e.g. emergency plans, disaster risk reduction plans, civil protection plans) but that do not explicitly focus or include a section on climate change. 


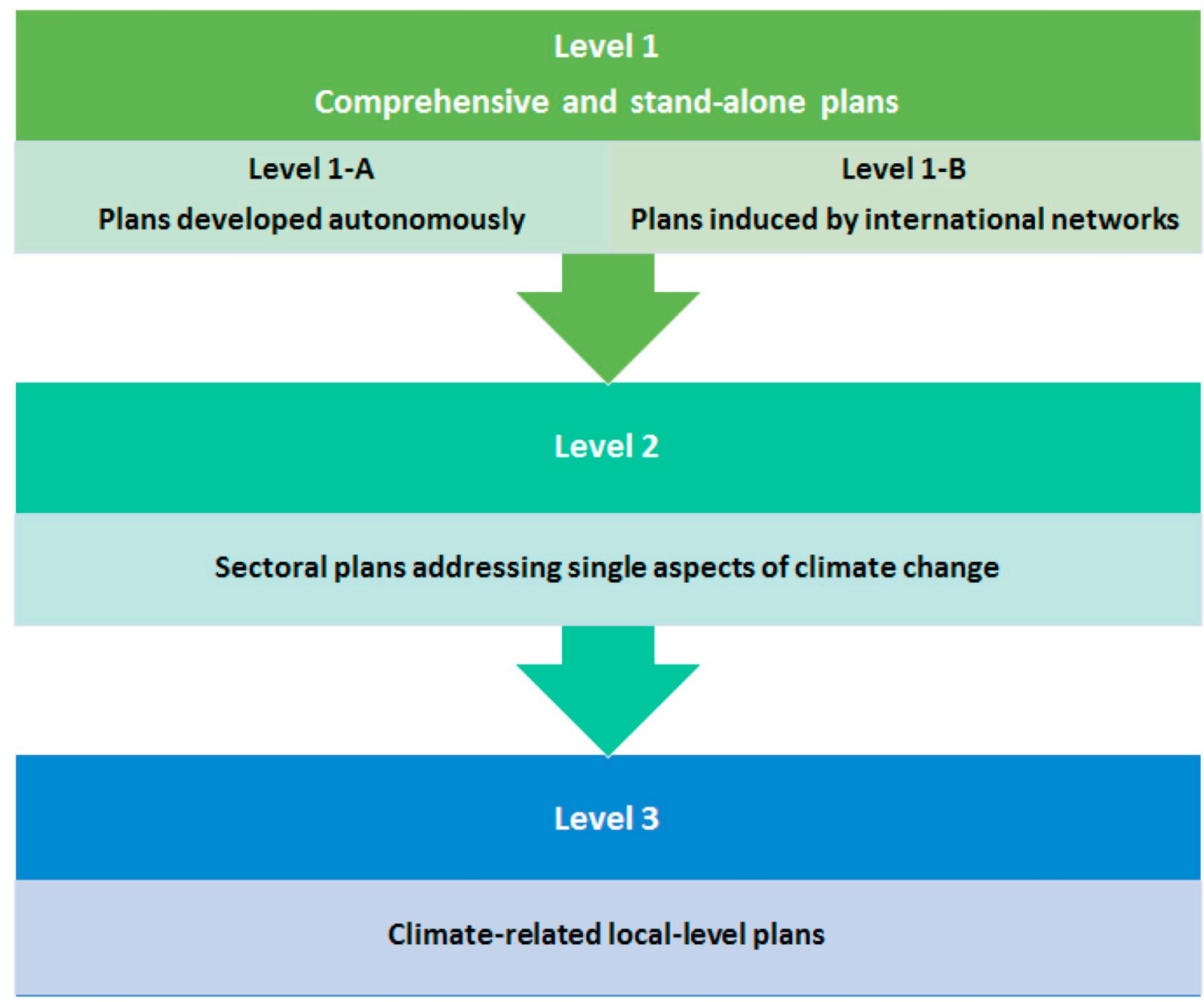

Fig. 1. Flowchart of LCPs review.

Level 1-3 plans were collected between October 2016 and May 2017 referring to international databases (e.g. made available by the Covenant of Mayors and Compact of Mayors) and through common search engines using keywords for mitigation and adaptation, such as: [city name] Strategia Cambiamenti Climatici (Climate Change Strategy); Piano di Azione Cambiamenti Climatici (Climate Change Action Plan); Cambiamenti Climatici ed Energia (Climate Change and Energy); Cambiamenti Climatici e Protezione Ambientale (Climate Change and Environmental Protection), Piano/Strategia di Adattamento Cambiamenti Climatici (Climate Change Adaptation Plan/Strategy), Piano/Strategia di Mitigazione Cambiamenti Climatici (Climate Change Mitigation Plan/ Strategy), Piano energetico comunale con riduzione di emissioni di CO2/ GHG (Municipal Energy Plans with CO2/GHG emission reductions); Piano anticaldo/Piano ondate di calore (Heatwave Plan); Piano di gestione rischio alluvione (Flood risk Plan), Piano di Protezione Civile (Civil Protection Plan), Piano di Emergenza (Emergency Plan), etc.

In addition to that, websites of local governments, municipalities and/or other authorities were checked with a special focus on those departments (e.g. planning, energy, sustainable development) that might cover climate action. In some cases, the municipality or planning department were contacted with regard to the municipality's climate actions and to request the related documents, if not available online.

The information gathered with this approach was organised in a shared database, taking into account for this study only the LCPs finalized and adopted by the city council or authority.

\subsection{The city sample}

For the Italian city sample, we referred to the urban areas included in the Urban Audit (UA-2015) database (Eurostat, 2015), which aims to provide statistics on a range of socioeconomic aspects relating to urban life in 885 cities spread across the EU Member States, Norway, Switzerland and Turkey. The Urban Audit delineates the "core city" according to political and administrative boundaries while the "larger urban zone" includes the core city and its commuter belt. The Urban Audit cities were selected in cooperation with the national Statistical Offices and are geographically dispersed to ensure a balanced and regionally representative sample which fit with the aims of our research.

In the specific case of Italy, the UA-2015 database (Eurostat, 2015) includes 76 large, as well as medium-sized cities for which we explored the state of local climate change response in terms of availability of Local Climate Plans (LCPs), as defined in Section 1. The main output of this activity is a database of LCPs on mitigation and adaptation already published. In case of more plans covering mitigation and/or adaptation we referred to the most recent plan adopted.

A sub-sample of cities was further selected to enter in the core phase of the research which dealt with an in-depth content analysis of the available LCPs. "Italian cities have been included in Urban Audit since the Pilot Phase (Roma, Milano, Napoli, Torino, Palermo, Genova, Firenze, Bari) then in UA-2 (Bologna, Catania, Venice, Verona, Cremona, Trento, Trieste, Perugia, Ancona, L'Aquila, Pescara, Campobasso, Caserta, Taranto, Potenza, Catanzaro, Reggio di Calabria, Sassari, Cagliari), and in UA-3 (Padova, Brescia, Modena, Foggia, Salerno)" (Bretagnolle et al., 2013). In this case we referred to the smaller sample of 32 cities included in the 2007 Urban Audit database (UA-3) of Eurostat (Eurostat, 2007). An analysis protocol and a set of indicators were defined as a common and transparent basis for the content analysis of plans in each one of the analysed cities. In Table 1, 
Table 1

Main features of the analysed city samples for Italy.

\begin{tabular}{ll}
\hline The UA-2015 IT city sample (76 cities) & The UA-3 IT city sample (32 cities) \\
\hline Steps of analysis & \\
1. Extraction of statistics & 1. Extraction of statistics \\
2. Availability of Local Climate Plans (LCPs) & 2. Availability of Local Climate Plans (LCPs) \\
& 3. Development of an analysis protocol and a set of indicators \\
& 4. Content analysis of plans
\end{tabular}

Cities included

Roma, Milano, Napoli, Torino, Palermo, Genova, Firenze, Bari, Bologna, Catania, Venezia, Verona, Cremona, Trento, Trieste, Perugia, Ancona, Pescara, Campobasso, Caserta, Taranto, Potenza, Catanzaro, Reggio di Calabria, Sassari, Cagliari, Padova, Brescia, Modena, Foggia, Salerno, Piacenza, Bolzano, Udine, La Spezia, Lecce, Barletta, Pesaro, Como, Pisa, Treviso, Varese, Busto Arsizio, Asti, Pavia, Massa, Cosenza, Carrara, Benevento, Sanremo, Savona, Vigevano, Matera, Viareggio, Acireale, Avellino, Pordenone, Biella, Lecco, Messina, Prato, Parma, Livorno, Reggio nell'Emilia, Ravenna, Ferrara, Rimini, Siracusa, Monza, Bergamo, Forlì, Latina, Vicenza, Terni, Novara, Giugliano in Campania

Geographical distribution

Northern: $53 \%$

Central: $14 \%$,

Southern: $33 \%$

Time framework of the analysis

October 2016-April 2017
Roma, Milano, Napoli, Torino, Palermo, Genova, Firenze, Bari, Bologna, Catania, Venezia, Verona, Cremona, Trento, Trieste, Perugia, Ancona, L'Aquila, Pescara, Campobasso, Caserta, Taranto, Potenza, Catanzaro, Reggio di Calabria, Sassari, Cagliari, Padova, Brescia, Modena, Foggia, Salerno the main features of this 2-step city analysis are represented.

\subsection{The analysis protocol for the 32 city sample}

An in-depth content analysis of the available LCPs was conducted on the subsample of 32 cities. It was based on an analysis protocol consisting of a set of specific indicators populated by means of an interactive procedure based on online forms and shared files.

In particular, the collecting-form of indicators was organised in two sections, one for mitigation and one for adaptation, each of them with a common introductory section collecting general information on the available plans, as reported in Table 2.

The next two sections of the collecting-form were aimed at gathering comprehensive information on the latest adopted plans on mitigation and adaptation. As concerns mitigation, the content analysis focused mainly on the existence of a baseline emission inventory and future projections, $\mathrm{CO}_{2} / \mathrm{GHG}$ emission reduction targets, mitigation topics included in plan and means and instruments to achieve them, actors involved, funding, communication aspects, monitoring and evaluation strategy and information on the local development framework. Similarly, for adaptation we looked at the impact/vulnerability inventory distinguishing among the different adaptation topics considered and the related means/instruments foreseen for the plan's implementation, actors involved, funding sources identified, communication strategies, monitoring strategies and additional information on the local framework in which the plan was developed. The whole list of topics, subtopics and research questions the analysis of LCPs was

Table 2

General information collected on the mitigation/adaptation plan/strategy.

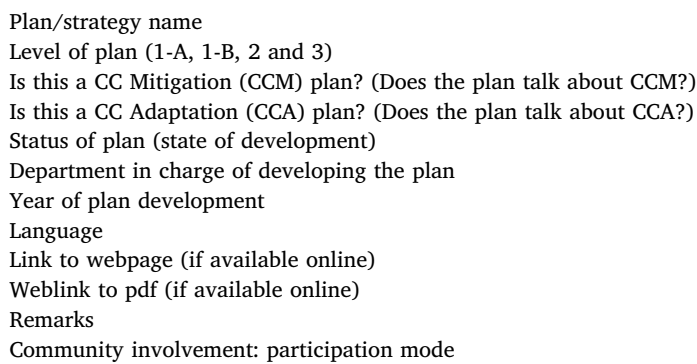

focused on is reported in Tables A.1 and A.2 of the Appendix A.

\section{Results and discussion}

In the following paragraphs a general assessment of climate planning in the 76 (UA-2015) Italian cities of the full sample will be presented, followed by a detailed content analysis of the smaller sample of 32 (UA-3) Italian cities.

\subsection{Availability of LCPs in 76 (UA-2015) Italian cities}

A comprehensive search of Local Climate Plans (LCPs) officially adopted and published in 76 (UA-2015) Italian cities was carried out between October 2016 and April 2017 in order to have a full picture of how Italian cities are committed to reduce carbon emissions and prepared for a changing climate. The results are presented according to the analysis framework introduced in the methodological section.

\subsubsection{Comprehensive and stand-alone plans (level 1)}

The analysis of comprehensive and stand-alone LCPs started with the search of stand-alone documents that are mitigation and/or adaptation plans developed autonomously by the urban authority/administration.

In Italy (Table 3), no city has an autonomous mitigation plan or a joint mitigation and adaptation plan whereas only 2 cities have a reference document on adaptation: Ancona (Local Adaptation Plan of the Municipality of Ancona, 2013) and Bologna (Adaptation Plan of the Municipality of Bologna, 2014). It is worth underlining that both documents were developed in the framework of EU LIFE projects: LIFE "act" for Ancona and LIFE "BLUEAP" for Bologna.

The picture varies significantly when we look at the planning documents developed on the basis of the commitment assumed by cities within the Covenant of Mayors: the Sustainable Energy Action Plans (SEAPs) define key actions that contribute to achieving the overall objective of reducing $\mathrm{CO}_{2}$ emissions by a minimum of $20 \%$ by the year 2020 , mainly through the promotion of energy efficiency and the use of renewable energy sources in a local authority's territory. Table 4 shows that 58 cities, that represent more than $76 \%$ of the UA sample, are members of the Covenant of Mayors (i.e. they are at Step 1 - Signature), $96.6 \%$ of them have developed a SEAP (having reached Step 2 - Action Plan submitted), and $26.3 \%$ of them have entered in the monitoring 
Table 3

Level 1-A plans in the 76 UA-2015 city sample for Italy.

\begin{tabular}{|c|c|c|c|c|c|c|c|c|}
\hline \multirow{2}{*}{$\begin{array}{l}\text { Italy } \\
\text { (76 UA Cities) }\end{array}$} & \multicolumn{2}{|c|}{ Mitigation plans } & \multicolumn{2}{|c|}{ Adaptation plans } & \multicolumn{2}{|c|}{ Joint plans } & \multicolumn{2}{|c|}{ No plans } \\
\hline & n. & $\%$ & n. & $\%$ & n. & $\%$ & n. & $\%$ \\
\hline Comprehensive and stand-alone documents - Autonomously developed (Level 1-A) & 0 & 0.0 & 2 & 2.6 & 0 & 0.0 & 74 & 97.4 \\
\hline
\end{tabular}

phase of the CoM (Step 3 - Results monitored).

On the other hand, none of these Italian cities have developed a Sustainable Energy and Climate Action Plan (SECAP) more recently introduced by the new Covenant of Mayors for Climate and Energy. The SECAP is expected within two years following the date of the local council decision and aims at addressing both climate mitigation and adaptation targets by the year 2030 based on a Climate Risks and Vulnerability Assessment and a Baseline Emission Inventory. In particular, "the adaptation strategy can either be part of the SECAP or developed and mainstreamed in a separate planning document" (Covenant of Mayors for Climate and Energy, 2018).

In addition, we analysed cities committed to the Compact of Mayors. In our sample (Table 4), only 5 cities committed to the Compact of Mayors (Roma, Milano, Bologna, Firenze, and Padova) but none of them have already developed a mitigation and/or adaptation plan in this framework. In other terms, all of these 5 cities are still at the first step of the adhesion path set up by the Compact of Mayors: 1 - Register commitment, 2 - Take inventory, 3 - Set reduction targets, 4 - Create either a joint or individual action plan to address climate mitigation and adaptation.

Fig. 2 shows how these comprehensive and stand-alone climate plans (Level 1) are distributed across Italy. Taking into account the geographical distribution of our 76 city sample (Northern - 53\%, Central - $14 \%$, Southern - 33\%) it is not surprising that $57 \%$ of the available SEAPs are concentrated in Northern Italy, followed by Southern Italy (30\%) and Central Italy (13\%).

On the other hand, cities without any climate plans are equally distributed between Northern (40\%) and Southern Italy (40\%), whereas the remaining $20 \%$ of cities are located in the central regions (Lazio, Marche, Toscana and Umbria).

With regard to the distribution of Local Climate Plans included in our 76 city sample in relation to the city size, Fig. 3 points out that the only 2 cities above 1,000,000 inhabitants (Roma and Milano), the 4 cities between 500,000 and 1,000,000 inhabitants (Napoli, Torino, Palermo and Genova) and 1 city below 50,000 inhabitants (Campobasso) have a Level 1-B plan (SEAP). On the other hand, looking at medium cities it can be observed that:

- 100,000-500,000 inhabitants: $82 \%$ of these cities have a SEAP; moreover, the only 2 cities with an adaptation plan (Bologna and Ancona) have also a SEAP.

- 50,000-100,000 inhabitants: 57\% of these cities have a SEAP.

4.1.2. Municipal energy plans and emergency plans (level 2 and level 3)

As concerns mitigation, only for those cities without a comprehensive plan (Level 1) we analysed the availability of sectoral mitigation plans and, in particular, of Municipal Energy Plans with a clear identification of a reduction target for $\mathrm{CO}_{2} / \mathrm{GHG}$ emissions. Among the 20 analysed cities without a SEAP only three (Perugia, Brescia and Avellino) have an energy plan. These energy plans provide some baseline $\mathrm{CO}_{2}$ emission or emission reduction scenarios but do not set $\mathrm{CO}_{2}$ or GHG emission reductions targets; thus, they were not considered as a sectoral mitigation plan for our analysis. As a result, the study identifies that in the 76 analysed cities Municipal Energy Plans do not replace the lack of comprehensive mitigation plans. Whereas, municipalities with more than 100,000 inhabitants have 24 months of the entry into force of Decree n. 257/2016 (14/01/2017) for preparing their Urban Plan for Sustainable Mobility which will allow to reduce atmospheric and acoustic pollution, greenhouse gas emissions, and energy consumption.

In the case of adaptation, there are not sectoral plans for the 74 cities without a comprehensive plan. Thus, most aspects related to adaptation are covered by Municipal Emergency Plans, which are compulsory by the Civil Protection national law (L. 100/2012) and are available in most of the analysed cities. On this, the research shows that Municipal Emergency Plans are substituting the lack of sectoral adaptation plans. However, they cannot substitute the adaptation plans because their rationale is different and somehow opposite: instead of focusing on prevent the unavoidable effects of climate change (proactive approach), their target is how to deal with emergency situations (post-event action).

\subsection{Content analysis of LCPs in 32 (UA-3) Italian cities}

Using the collecting form reported in the Appendix (Tables A.1 and A.2), an in-depth analysis of the content of mitigation and adaptation plans of the sample of 32 (UA-3) Italian cities was carried out in May 2017. Mitigation and adaptation actions and strategies included in the LCPs available were analysed, as described in the following.

\subsubsection{Mitigation}

As already said for the larger sample of 76 (UA-2015) Italian cities, no comprehensive mitigation plan autonomously developed (Level 1-A) is currently available but we found a predominance of LCPs of Level 1-B that are plans developed within international urban climate networks, such as Covenant of Mayors. The great success achieved in Italy by the Covenant of Mayors is demonstrated by the fact that $78 \%$ of cities in our smaller sample of 32 cities have already developed their Sustainable Energy Action Plan (SEAP) in the framework of this European network. None of the analysed cities have sectoral plans of Level 2 such as municipal energy plans including $\mathrm{CO}_{2} / \mathrm{GHG}$ emission reduction targets, whereas the remaining $22 \%$ of cities have no kind of mitigation plan.

Table 4

Level 1-B plans in the 76 UA-2015 city sample for Italy.

\begin{tabular}{|c|c|c|c|c|c|c|c|c|c|c|}
\hline \multirow[t]{2}{*}{$\begin{array}{l}\text { Italy } \\
\text { (76 UA Cities) }\end{array}$} & \multicolumn{2}{|c|}{$\begin{array}{l}\text { CoM members (UA } \\
\text { cities) }\end{array}$} & \multicolumn{2}{|c|}{$\begin{array}{l}\text { CoM members (UA } \\
\text { cities) } \\
\text { with a SEAP }\end{array}$} & \multicolumn{2}{|c|}{$\begin{array}{l}\text { CoM members (UA } \\
\text { cities) } \\
\text { with a SECAP }\end{array}$} & \multicolumn{2}{|c|}{$\begin{array}{l}\text { Compact members } \\
\text { (UA cities) }\end{array}$} & \multicolumn{2}{|c|}{$\begin{array}{l}\text { Compact members (UA cities) } \\
\text { with a plan developed }\end{array}$} \\
\hline & n. & $\%$ & n. & $\%$ & n. & $\%$ & n. & $\%$ & n. & $\%$ \\
\hline $\begin{array}{l}\text { Comprehensive and stand-alone documents - } \\
\text { Internationally induced (Level 1-B) }\end{array}$ & 58 & 76.3 & $56\left({ }^{\mathrm{a}} 20\right)$ & $73.7\left({ }^{\mathrm{a}} 26.3\right)$ & 0 & 0.0 & 5 & 0.1 & 0 & 0.0 \\
\hline
\end{tabular}

\footnotetext{
${ }^{\text {a }}$ Cities with a monitored SEAP.
} 


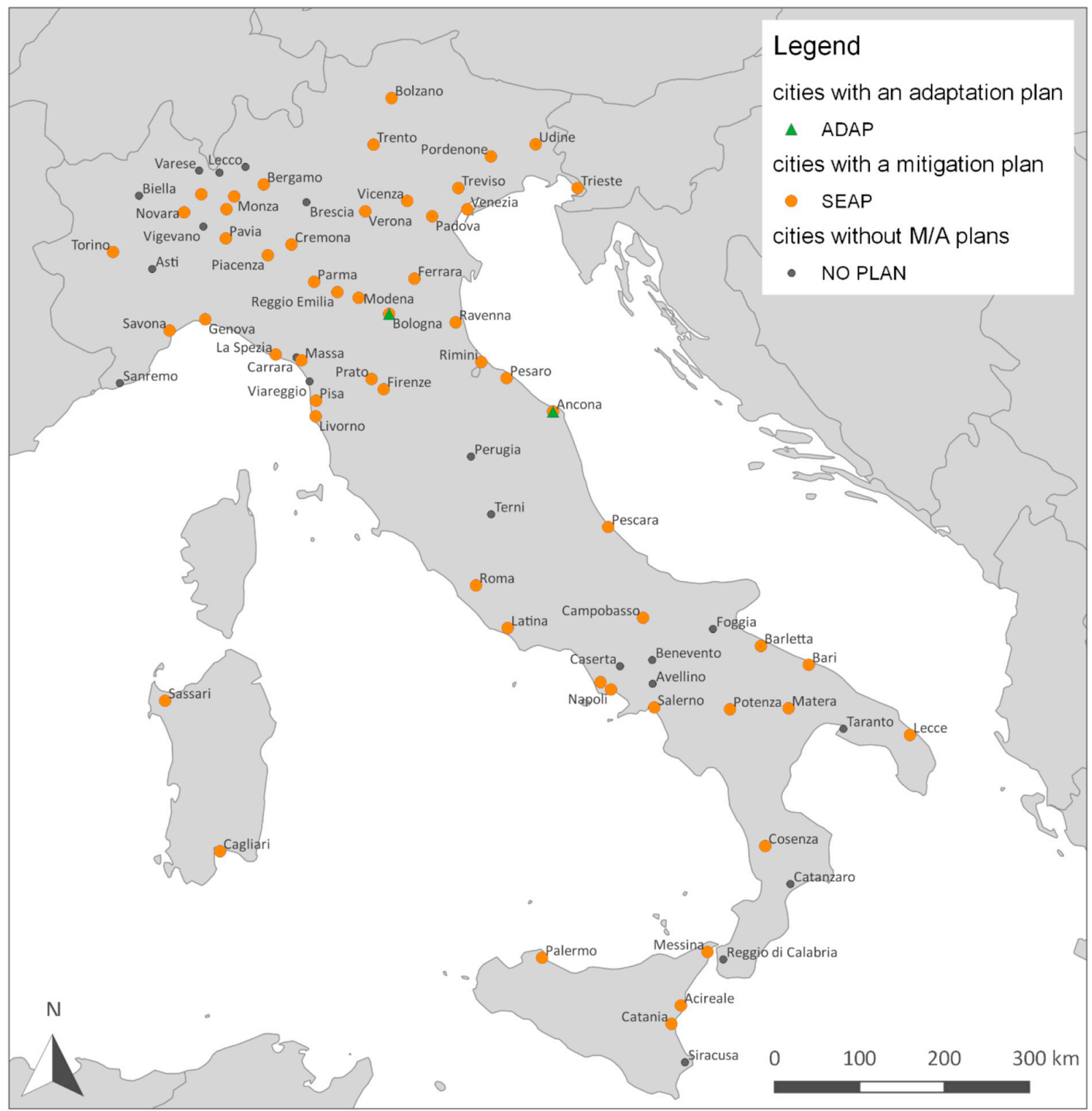

Fig. 2. Comprehensive and stand-alone plans (Level 1) in the 76 UA-2015 city sample for Italy.

Table 5 summarises the status of mitigation planning in the cities of the sample.

Focusing on SEAPs and, in particular on the mitigation targets, Fig. 4 represents for each analysed city: 1) the $\mathrm{CO}_{2} / \mathrm{GHG}$ emission targets; 2) the baseline years related to emission reduction targets; 3 ) the target years (2020 for all cities, in compliance with the Covenant of Mayors rules). It shows that only 2 cities (Roma and Cremona) have set reduction targets on GHG emissions whereas most of the SEAPs refer to $\mathrm{CO}_{2}$ emissions, $70 \%$ of them setting reduction targets for 2020 higher than $20 \%$.

Looking at the actions proposed by plans in order to reach the mitigation targets, it can be noted that all the plans rely on energy efficiency measures, energy savings, and sustainable transportation. In particular, all the analysed plans promote actions aimed at increasing energy performances in old municipal buildings, upgrading the municipal fleet and promoting local public transport, smart mobility system, cycling, walking, car sharing/pooling, and electric cars. Moreover, an increase of energy production from renewable sources, mainly through the implementation of PV, solar thermal and biomass, is promoted by $96 \%$ of the analysed plans.

In order to boost the proposed measures, $96 \%$ of the plans aim at increasing citizens' awareness on energy and environmental issues closely related to the reduction of $\mathrm{GHG} / \mathrm{CO}_{2}$ emissions through the activation of soft measures such as information campaigns, thematic meetings with the involvement of schools and communities. Moreover, it can be pointed out that most of the analysed SEAPs were developed between 2009 and 2015 with a peak in 2012 (36\%) by the administration itself, sometimes in collaboration with universities or research centers or with the support of consultancy firms. Only a $12 \%$ of plans were implemented in the framework of EU projects.

\subsubsection{Adaptation}

As concerns adaptation, as already said, only Bologna and Ancona developed a comprehensive stand-alone adaptation plan (Level 1-A). In particular, the Ancona's adaptation plan was drafted within the Life project "ACT - Adapting to Climate change in Time" in 2013, whose 


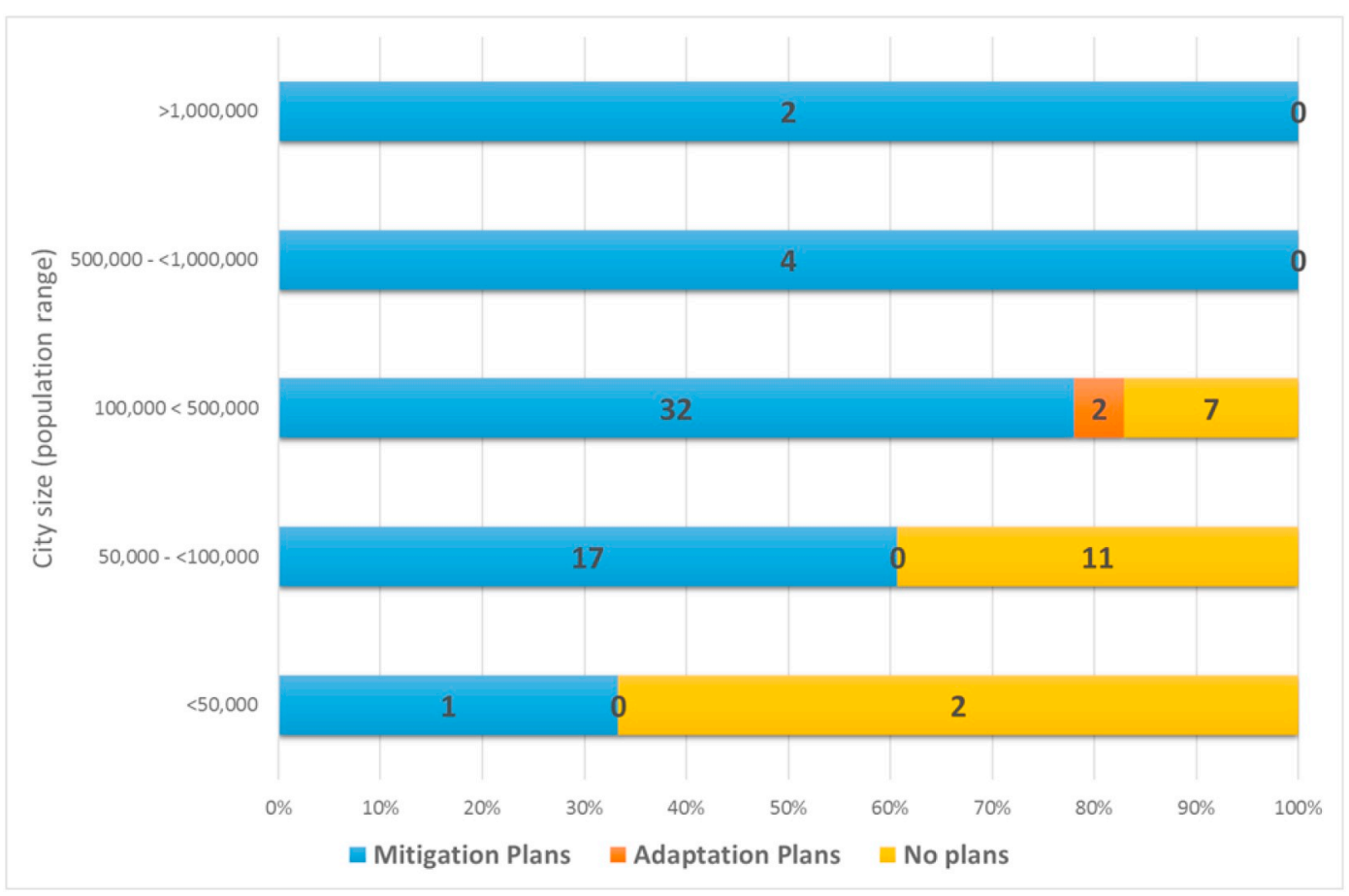

Fig. 3. Distribution of the Level 1 plans per city size.

main focus was to develop a process for an effective municipal strategy for local climate change adaptation measures. The main vulnerabilities addressed by this plan are: landslides, coastal erosion, infrastructures, cultural heritage and heatwaves, paying particular attention on soft measures to raise citizens' awareness, like for example the establishment of a naturalistic laboratory. Likewise, Bologna developed its adaptation strategy in the framework of the Life project "BLUE AP Bologna Local Urban Environment Adaptation Plan for a Resilient City" in 2014. This strategy focuses on several vulnerabilities of the city (extreme rain events and hydrogeologic risk, heat waves, freshwater scarcity and droughts) introducing different proposals that will be realized within a structured action plan.

On the other hand, as shown in Fig. 5, most of the analysed cities have developed a Level 3 plan namely "Related to Climate Change plan". In particular, $81 \%$ of the city sample (26 municipalities) has a Municipal Emergency Plan developed in compliance with the Civil Protection national law (L. 100/2012) that obliges all municipalities to implement a plan dealing with emergencies due to natural disasters. In particular, these plans aim at assuring the safety of population, focusing on topics that are relevant also to climate change (even if it is not explicit mentioned) as for example flood risk and heatwaves. As a matter of fact, $85 \%$ of the analysed plans handles flood risk and $15 \%$ of them address heatwaves.

The remaining four cities (Bari, Palermo, Campobasso, and Caserta) of our sample register a strong delay on the adaptation front since they have no plan at all.

In this general framework it is important to underline that other cities are on track towards the implementation of an adaptation plan, as for example Venice that in 2014 approved the document "Venice Future Climate" (Venezia Clima Futuro) that lays the foundation for the development of a Climate Change Adaptation Plan for the city. Another example is represented by Padova that, already in 2011 integrated a chapter on climate change adaptation in its SEAP (SEAP, 2011) developed in the framework of the EU LIFE-LAKS project (LIFE-LAKS EU project). Moreover, in 2016, in cooperation with the University of Venice, Padova drafted the "Guidelines for the implementation of a Climate Change Adaptation Plan" which represent a good starting point for the development of a structured adaptation plan.

\section{Conclusions}

Today, the scientific community and many international

Table 5

Territorial distribution of mitigation plans in the 32 UA-3 city sample for Italy.

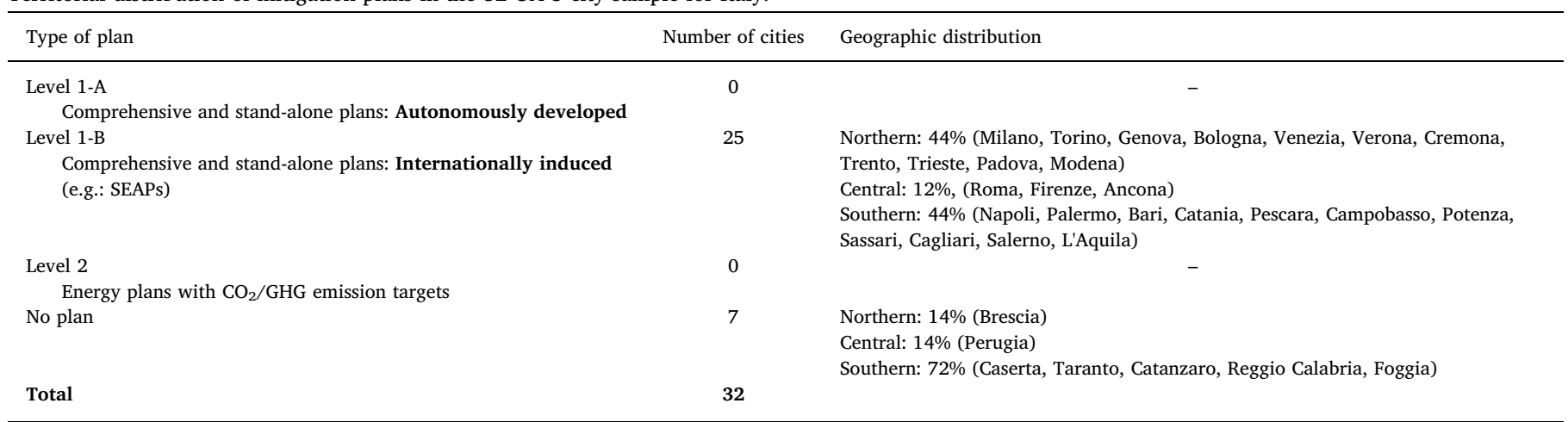




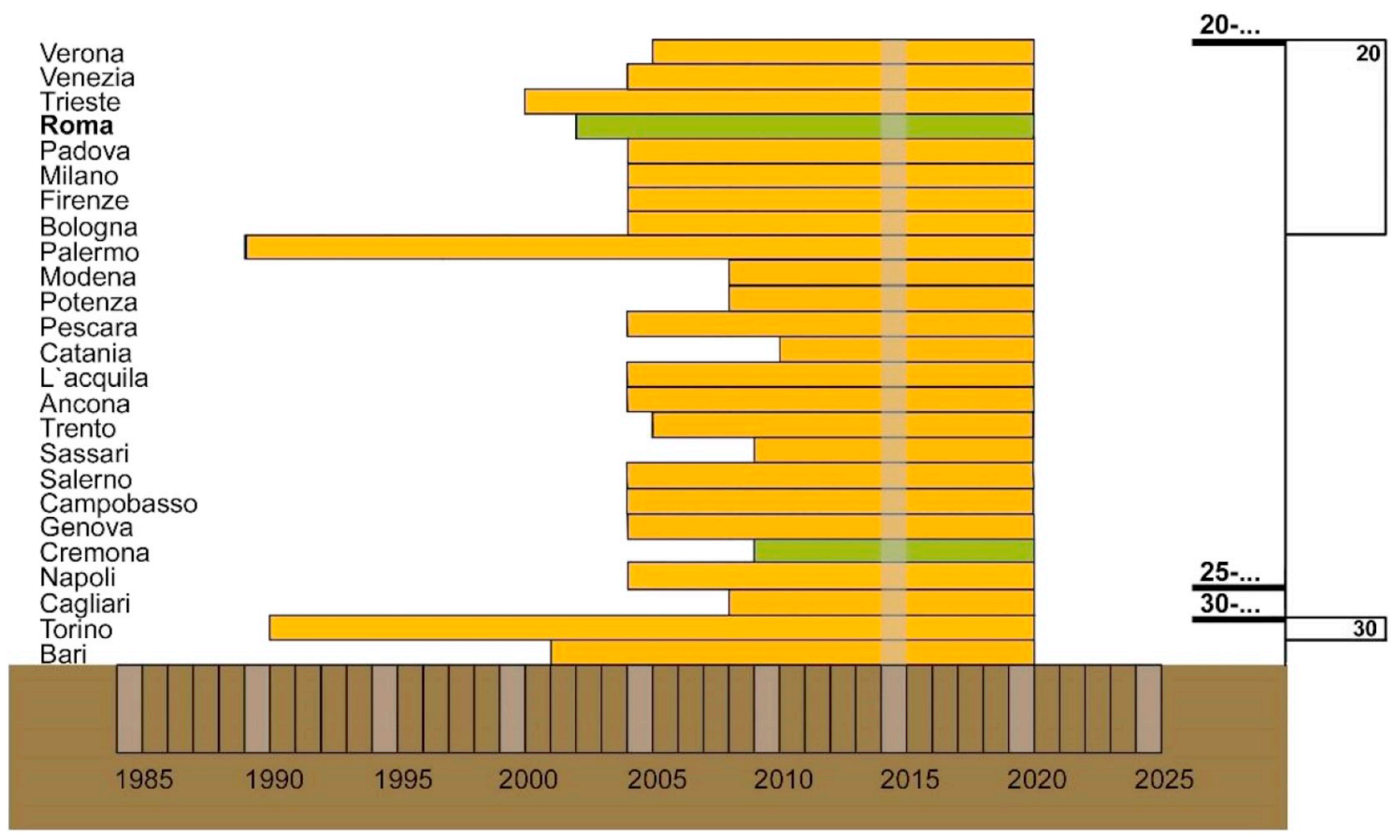

Fig. 4. Carbon tree: $\mathrm{CO}_{2} / \mathrm{GHG}$ emission targets in the 32 (UA-3) city sample.

organizations and networks recommend to tackle the challenge of climate change at local level. First, because cities welcome most of the European population and secondly because several cities directly suffer negative effects of climate change such as landslides, floods, drought and heatwaves.

In order to be ready to build climate-proof cities, municipalities have to engage themselves in reducing greenhouse gases, that are the main responsible of global warming, and creating climate resilient cities. This study assessed how Italian cities are engaged in such a climate planning activity through the analysis of the status of local climate planning in a representative sample of Italian cities. This analysis can be useful to derive some general recommendations useful to improve both the plans and the policy framework in which urban climate plans are developed.

Planning for mitigation and adaptation in Italy is being characterized as a dynamic process, where the policy framework is quickly evolving and more and more cities are engaging in climate actions. In particular, there is no national legislation that obliges cities to act in terms of mitigation or adaptation. Thus the development and implementation of climate plans is entrusted to local initiatives.

In this paper we found that most Italian cities pay great attention to climate change, even if much more to mitigation than to adaptation, due to historical reasons and the long experience gained in energy planning. The engagement in mitigation is demonstrated by the large number of cities that have voluntarily joined the Covenant of Mayors initiative and that have developed mitigation plans carrying out decarbonization strategies: more than $73 \%$ of cities in our sample of 76 cities, and $78 \%$ of the smaller sample of 32 cities are equipped with a SEAP in which a $\mathrm{CO}_{2} / \mathrm{GHG}$ target was set. Regarding their commitment within the Covenant of Mayors, the content analysis of 32 Italian cities, showed that over the $50 \%$ of cities have set a $\mathrm{CO}_{2} / \mathrm{GHG}$ targets for 2020 higher than $20 \%$ (the mandatory target). On the other hand it pointed out that about one-third of the available SEAPs were elaborated by the administration itself, in some cases benefitting from external technical support.

On the adaptation side, only Bologna and Ancona in our sample approved their adaptation plan/strategy, respectively in 2014 and 2013. Few other cities have started the planning process to identify climate vulnerabilities. This may be attributable to the lack of a national adaptation framework until 2014, when the National Adaptation
Strategy was approved whereas the National Action Plan is still missing. Another relevant reason is the fact that often planning systems already exist for climate change-related risks such as hydraulic and hydrogeologic, mainly at provincial and regional level. This aspect could discourage cities on taking further action, considering also the general lack of economic resources.

Despite this, the study reveals that Italian cities are trying to catch up. A strong boost was given by international networks, such as Mayors Adapt and the Compact of Mayors, and by European funding programmes as LIFE that represent good opportunities for the most dynamic cities for gathering resources and implement adaptation plans. In fact, the study identifies how cities are making the most of the practical support, guidance and tools provided by the instruments mentioned. The exploitation of EU funding opportunities can support willing cities in developing plans and implementing actions.

The overall analysis of the policies and plans evaluated confirms a trend towards an increasing awareness on climate mitigation whereas the scarcity of local adaptation plans confirms that urban resilience is a very complex issue that Italian cities are addressing mainly with a sectoral reactive approach on civil security. Thus, while they address a relevant number of interrelated fields, the study suggests that Italian cities should apply a more cross-sectoral and holistic approach in the development of their strategies in order to avoid maladaptation and exploit trade-offs (synergies and opportunities) among mitigation and adaptation actions.

As a matter of fact, for the Italian context integration of mitigation and adaptation actions in local planning systems can represent a possible operative solution to maintain, in the long term, the expected results of local actions as well as to counteract carbon emission and reducing potential impacts of climate extreme events on cities. The scenario revealed by this study suggests also that cities needs the support and coordination of upper levels of government, to undertake climate action in a more systematic way. In this regard the new policy framework on adaptation that is being setting by the national government and some first examples of regional climate change plans (e.g. Abruzzo Region) could represent a step forward provided that local action will receive the necessary attention in terms of policy construction and provision of the necessary technical and financial resources.

Because citizens have a potentially important role in achieving the 


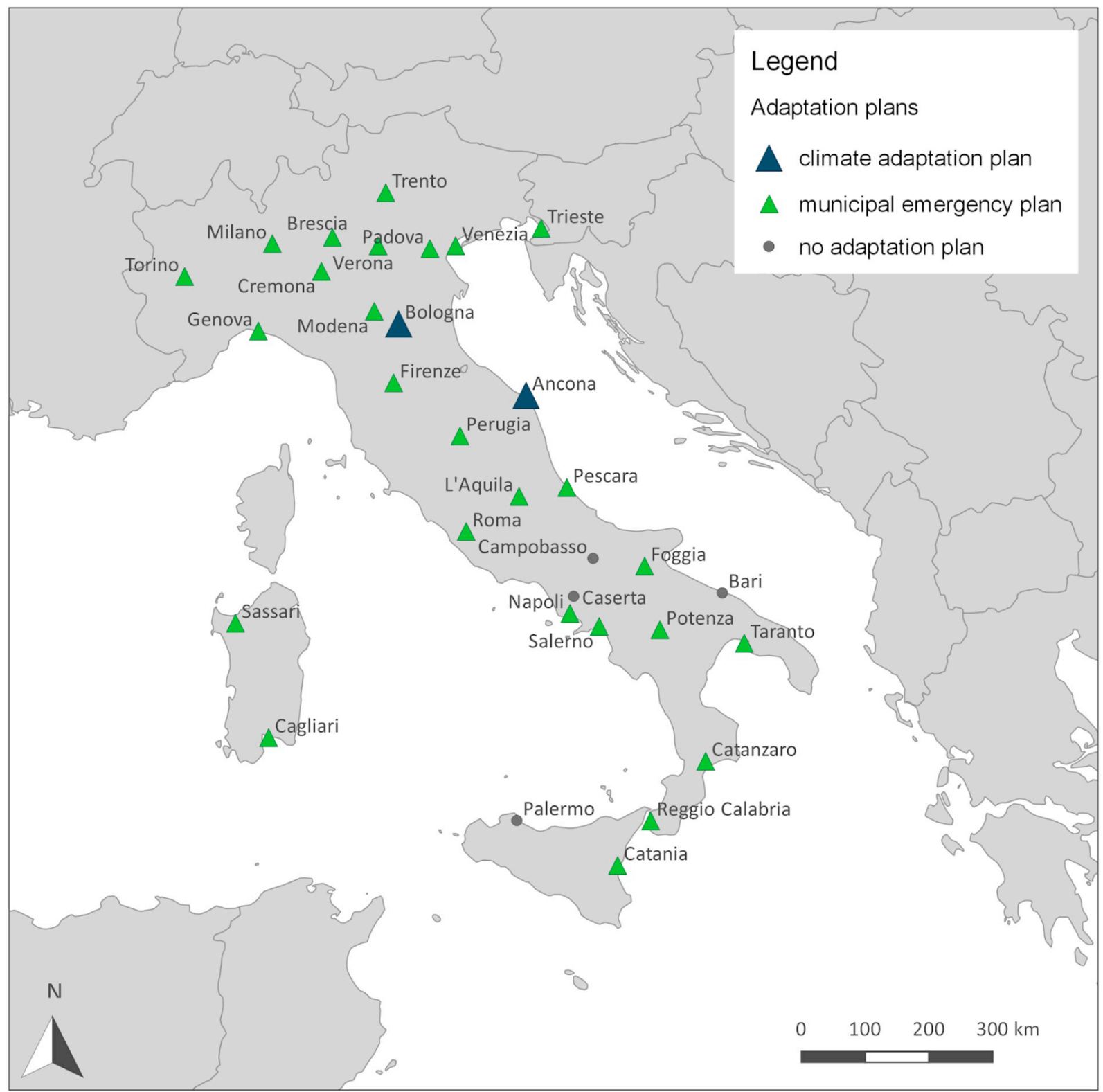

Fig. 5. Adaptation plans (Level 1-A and Level 3) in the 32 UA-3 city sample.

targets set by the local climate plans, municipalities need to involve citizens, sectoral practitioners, stakeholders in all the implementation phases of the plans. Thus, a continuous communication and information flow has to be assured in order to achieve better informed population and good cooperation in reaching goals and cope with threats of climate change, designing and promoting an ad-hoc education and outreach campaign focused on behaviour change also through online and social media campaigns. Several experiences carried out so far have demonstrated how important is to target schools to reach households.

Furthermore, the Italian case study shows that climate networks have represented a crucial role in initiating and supporting cities on mitigation and adaptation planning, and they continue to represent a relevant framework to consolidate this trend in the medium term. This is particularly true for the Covenant of Mayors which has boosted, in the latest years, Italian cities to start developing mitigation plans
(SEAPs). It is hoped that this process will be strengthened through the new integrated Covenant of Mayors for Climate \& Energy stimulating municipalities at joining it and boosting the implementation of integrated mitigation and adaptation plans (i.e. the Sustainable Energy and Climate Action Plans - SECAPs). This challenge will interest also cities with an existing SEAP that will be able to upgrading the existing SEAP to also include reporting for 2030 commitments and adaptation.

This will help keep the momentum of climate action in Italian cities and support the integration of adaptation concepts in urban planning.

\section{Acknowledgements}

This research did not receive any specific grant from funding agencies in the public, commercial, or

not-for-profit sectors. 


\section{Appendix A}

Table A.1

Mitigation section in the second part of the collecting-form.

\begin{tabular}{|c|c|}
\hline Topics & Subtopics and research questions \\
\hline \multirow[t]{6}{*}{ Emission inventory } & Does the plan include a baseline emission inventory (i.e. of current emissions)? \\
\hline & Does the plan include future emission projections? \\
\hline & Does the future emission projection use multiple scenarios? \\
\hline & Which scenario has been chosen for mitigation efforts? \\
\hline & Type of diagnosis \\
\hline & Remarks \\
\hline \multirow[t]{12}{*}{ Emission reduction targets } & Are there any quantitative mitigation targets? \\
\hline & Emission target [city $\mathrm{CO} 2$, in \%] \\
\hline & Baseline year \\
\hline & Target year \\
\hline & Comments \\
\hline & Emission target [city GHG, in \%] \\
\hline & Baseline year \\
\hline & Target year \\
\hline & Comments \\
\hline & Other quantitative targets \\
\hline & Other targets \\
\hline & Comments \\
\hline \multirow[t]{11}{*}{ Mitigation topics included in plan } & Energy saving \\
\hline & Energy efficiency \\
\hline & Energy provision \\
\hline & Renewable energies \\
\hline & Kind of renewable energy addressed \\
\hline & Waste management \\
\hline & Urban greenery/agriculture/forestry \& parks \\
\hline & Transportation \\
\hline & Kind of transport \\
\hline & Municipal buildings and operations \\
\hline & other buildings and building management \\
\hline \multirow[t]{5}{*}{ Mitigation means/instruments } & Hard measures \\
\hline & Soft measures \\
\hline & Financial measures \\
\hline & Information campaigns \\
\hline & Institutional, organisation aspects \\
\hline \multirow[t]{2}{*}{ Actors: } & Who is implementing the actions? \\
\hline & Who is mostly benefiting from the mitigation actions? \\
\hline Mitigation funding & Who paid for the development of the mitigation plan? \\
\hline \multirow[t]{2}{*}{ Communication } & Is there a communication strategy accompanied to the implementation of mitigation? \\
\hline & How will the actions be made known to the community? \\
\hline Mitigation monitoring & Is there a monitoring \& evaluation strategy/plan (controlling mechanism) attached to the mitigation process? \\
\hline \multirow{7}{*}{ Information on the local development framework: } & Done as part of EU-project? \\
\hline & Done in combination with university/research center? \\
\hline & Done by a consultancy firm? \\
\hline & Done by the administration itself? \\
\hline & Has international knowledge been used? \\
\hline & Has national framework information been used? \\
\hline & Has regional (sub-national) framework information been used? \\
\hline
\end{tabular}

Table A.2

Mitigation section in the second part of the collecting-form.

\begin{tabular}{ll}
\hline Topics & Subtopics and research questions \\
\hline Impact/vulnerability inventory & Does the plan include a CURRENT risk or vulnerability assessment? \\
Which type of CURRENT risk or vulnerability assessment? & Does the plan include a FUTURE risk or vulnerability assessment? \\
& Which type of FUTURE risk or vulnerability assessment? \\
& Are the impacts on vulnerable groups addressed? \\
& Which groups are addressed? \\
& Does the plan include CC scenarios? \\
& Type of scenarios \\
& Are community views collected when developing the vulnerability assessment or adaptation plan? \\
& Electricity/energy management \\
Adaptation topics & Water quantity management \\
& Health aspects \\
Urban greenery/agriculture/forestry \& parks & Transport \\
Kind of transport \\
Municipal buildings and operations
\end{tabular}


Table A.2 (continued)

\begin{tabular}{|c|c|}
\hline Topics & Subtopics and research questions \\
\hline & Other building management \\
\hline \multirow[t]{5}{*}{ Adaptation means/instruments } & Hard measures \\
\hline & Soft measures \\
\hline & Financial measures \\
\hline & Information campaigns \\
\hline & Institutional, organisation aspects \\
\hline \multirow{2}{*}{ Actors } & Who is implementing the actions? \\
\hline & Who is mostly benefiting from the adaptation actions? \\
\hline Adaptation funding & Who paid for the development of the adaptation plan? \\
\hline \multirow{2}{*}{ Communication } & Is there a communication strategy accompanied to the implementation of adaptation? \\
\hline & How will the actions be made known to the community? \\
\hline Adaptation monitoring & Is there a monitoring \& evaluation strategy/plan (controlling mechanism) attached to the adaptation process? \\
\hline \multirow[t]{7}{*}{ Information on the local development framework } & Was it done as part of EU-project? \\
\hline & Was it done in combination with university/research center? \\
\hline & Was it done by a consultancy firm? \\
\hline & Was it done by the administration itself? \\
\hline & Has international knowledge been used? \\
\hline & Has national framework information been used (i.e. out of national guidelines, national adaptation plans, etc.)? \\
\hline & Has regional (sub-national) framework information been used (i.e. out of regional guidelines, regional adaptation plans, etc.)? \\
\hline
\end{tabular}

\section{References}

Baker, I., Peterson, A., Brown, G., \& McAlpine, C. (2012). Local government response to the impacts of climate change: An evaluation of local climate adaptation plans. Landscape and Urban Planning, 107(2), 127-136. https://doi.org/10.1016/j. landurbplan.2012.05.009.

Bretagnolle, A., Delisle, F., Mathian, H., Lizzi, L., Guéroi, M., \& Averlant, G. (2013). Technical report. LUZ specifications (Urban Audit 2004). ESPON 2013 Database https://www.espon.eu/sites/default/files/attachments/3.6_TR-Urban_Audit.pdf, Accessed date: 13 September 2018

Church, J. M. (2013). A study of international experience on adaptation and climate protection at the local level: Great Britain, Italy, Poland. Tbilisi. In National Association of Local Authorities of Georgia (Ed.). Italy (pp. 89-170). . http://nala.ge/ climatechange/uploads/Studies/StudyofInternationalExperienceon_ENG.pdf.

Compact-of-Mayors-Full-Guide_July2015 (2017). https://www.compactofmayors.org/ history/, Accessed date: 23 November 2017.

Covenant of Mayors for Climate and Energy (2018). https://www.covenantofmayors.eu/ en/, Accessed date: 5 September 2018

De Gregorio Hurtado, S., Olazabal, M., Salvia, M., Pietrapertosa, F., Olazabal, E. Geneletti, D., ... Reckien, D. (2014). Implications of governance structures on urban climate action: Evidence from Italy and Spain. BC3 working paper series. vol. 2.

De Gregorio Hurtado, S., Olazabal, M., Salvia, M., Pietrapertosa, F., Olazabal, E., Geneletti, D., ... Reckien, D. (2015). Understanding how and why cities engage with climate policy. An analysis of local climate action in Spain and Italy. Tema (Special Issue ECCA 2015). Journal of Land Use, Mobility and Environment, 8, 23-46. https:// doi.org/10.6092/1970-9870/3649.

Decree of the Ministry of Infrastructure and Transport n. 257, art. 3 (2016). Urban Plan for Sustainable Mobility - Decreto del ministero delle Infrastrutture e dei trasporti 4 agosto 2017. Individuazione delle linee guida per i piani urbani di mobilità sostenibile, ai sensi dell'articolo 3, comma 7, del decreto legislativo 16 dicembre 2016, n. 257.

EC, European Commission - Press release (2016). EU Covenant of Mayors and Compact of Mayors launch largest global coalition of cities committed to fighting climate change. Brussels, 22 June 2016. http://europa.eu/rapid/press-release_IP-16-2247_it.htm, Accessed date: 23 November 2017.

EEA European Environmental Agency, Report. N. 3 (2013). Adaptation in Europe. Addressing risks and opportunities from climate change in the context of socio-economic developments.

Eurostat (2007). Urban Audit (UA-3). European Regional and Urban Statistics Reference Guide. Eurostat Methodologies and working papers. http://ec.europa.eu/eurostat/ ramon/statmanuals/files/KS-RA-07-005-EN.pdf, Accessed date: 13 September 2018

Eurostat (2015). Urban Audit (UA-2015). Annex 2 - Cities participating in the Urban Audit data collection. https://ec.europa.eu/eurostat/documents/4422005/6840613/ RYB-2015-Annex2-Cities-CandK.pdf, Accessed date: 13 September 2018.

Geels, F. W. (2011). The role of the cities in technological transitions: Analytical clarifications and historical examples. In H. Bulkeley, V. C. Broto, M. Hodson, \& S. Marvin (Eds.). Cities and low carbon transitions (pp. 13-28). New York: Routledge.

Geneletti, D., \& Zardo, L. (2016). Ecosystem-based adaptation in cities: An analysis of European urban climate adaptation plans. Land Use Policy, 50, 38-47. https://doi. https://doi.org/10.1016/j.landusepol.2015.09.003.

Gouldson, A., Colenbrander, S., Sudmant, A., Godfrey, N., Millward-Hopkins, J., \& Fang, W. (2015). et al. Accelerating Low-Carbon Development in the World's Cities. Contributing paper for Seizing the Global Opportunity: Partnerships for Better Growth and a Better ClimateLondon and Washington, DC: New Climate Economy. Available at: http:// newclimateeconomy.report/misc/working-papers.

Heidrich, O., Dawson, R. J., \& Reckien, D. (2013). Walsh CL. Assessment of the climate preparedness of 30 urban areas in the UK. Climatic Change, 120, 771-784.
Heidrich, O., Reckien, D., Olazabal, M., Foley, A., Salvia, M., De Gregorio Hurtado, S., .. Dawson, R. J. (2016). National climate policies across Europe and their impacts on cities strategies. Journal of Environmental Management, 168(3), 36-45.

Adaptation Plan of the Municipality of Bologna - Local Adaptation Strategy - Piano di Adattamento della Città Di Bologna. Strategia di adattamento locale. http://www. comune.bologna.it/sites/default/files/documenti/Allegato_Strategia\%20di \%20adattamento\%20locale.pdf, Accessed date: 23 November 2017.

ICLEI - International Council for Local Environmental Initiatives (2010). Changing Climate, Changing Communities: Guide and Workbook for Municipal Climate Adaptation. Toronto: ICLEI Canada.

IMELS (2014). Italian Ministry for the Environment, Land and Sea, 2014, Elements for a National Strategy for Adaptation to Climate Change - Elementi per una Strategia Nazionale di Adattamento ai Cambiamenti Climatici. http://www.minambiente.it/ sites/default/files/archivio/allegati/clima/snacc_2014_elementi.pdf, Accessed date: 24 November 2017.

IPCC (2012). In C. B. Field, V. Barros, T. F. Stocker, D. Qin, D. J. Dokken, K. L. Ebi, M. D. Mastrandrea, K. J. Mach, G.-K. Plattner, S. K. Allen, M. Tignor, \& P. M. Midgley (Eds.). Managing the Risks of Extreme Events and Disasters to Advance Climate Change Adaptation. A Special Report of Working Groups I and II of the Intergovernmental Panel on Climate ChangeCambridge, UK, and New York, NY, USA: Cambridge University Presshttps://www.ipcc.ch/pdf/special-reports/srex/SREX Full Report.pdf.

Italian Law 10/1991 (1991). Standards for the implementation of the national energy plan for energy rational use, energy saving and development of renewable energy sources - Norme per l'attuazione del piano energetico nazionale in materia di uso razionale dell'energia, di risparmio energetico e di sviluppo delle fonti rinnovabili di energia.

Kumar, P., \& Geneletti, D. (2015). How are climate change concerns addressed by spatial plans? An evaluation framework, and an application to Indian cities. Land Use Policy, $42,210-226$.

Legambiente (2018). SOS Acqua: Nubifragi, siccità, ondate di calore: le città e i territori alla sfida del Clima. https://www.legambiente.it/sites/default/files/images/ rapporto cittaclima2018.pdf, Accessed date: 4 October 2018.

LIFE-LAKS EU project - Local Accountability for Kyoto Goals http://space.comune.re.it/ laks/web/, Accessed date: 5 October 2018.

Local Adaptation Plan of the Municipality of Ancona Piano di adattamento del Comune di Ancona (2013). Available at: http://www.actlife.eu/medias/260actpianoadattamentoancona.pdf, Accessed date: 23 November 2017.

Measham, T. G., Preston, B. L., Smith, T. F., Brooke, C., Gorddard, R., Withycombe, G., et al. (2011). Adapting to climate change through local municipal planning: Barriers and challenges. Mitigation and Adaptation Strategies for Global Change, 16(8), 889-909. https://doi.org/10.1007/s11027-011-9301-2.

MISE (2017). Italian Ministry of Economic Development, 2017. Italy's National Energy Strategy. Available at: http://www.sviluppoeconomico.gov.it/images/stories/ documenti/BROCHURE_ENG_SEN.PDF.

Picketts, I. M., Déry, S. J., \& Curry, J. A. (2013). Incorporating climate change adaptation into local plans. Journal of Environmental Planning, 57(7), 984-1002. https://doi.org/ 10.1080/09640568.2013.776951.

Pietrapertosa, F., Khokhlov, V., Salvia, M., \& Cosmi, C. (2018). Climate change adaptation policies and plans: A survey in 11 South East European countries. Renewable and Sustainable Energy Reviews, 81, 3041-3050. https://doi.org/10.1016/j.rser.2017.06. 116.

Reckien, D., Flacke, J., Dawson, R. J., Heidrich, O., Olazabal, M., Foley, A., .. Pietrapertosa, F. (2014). Climate change response in Europe: what's the reality? Analysis of adaptation and mitigation plans from 200 urban areas in 11 countries. Climatic Change, 122(1-2), 331-340. https://doi.org/10.1007/s10584-013-0989-8.

Reckien, D., Flacke, J., De Gregorio Hurtado, S., Salvia, M., Heidrich, O., Dawson, R. J., .. Pietrapertosa, F. (2014). Understanding cities: advances in integrated assessment of urban sustainability, Newcastle. In R. J. Dawson, A. Wyckmans, O. Heidrich, J. 
Köhler, S. Dobson, \& E. Feliu (Eds.). Urban climate change response and the impact of climate networks in Europe (pp. 45-52). 978-0-9928437-0-0.

Reckien, D., Flacke, J., Olazabal, M., \& Heidrich, O. (2015). The influence of drivers and barriers on urban adaptation and mitigation plans: An empirical analysis of European cities. PLoS One, 10(8), e0135597. https://doi.org/10.1371/journal.pone.0135597.

Reckien, D., Salvia, M., Heidrich, O., Church Filomena Pietrapertosa, J. M., De GregorioHurtado, S., D'Alonzo, V., ... Dawson, R. (2018). How are European cities planning to respond to climate change? Analysis of local climate plans from 885 urban areas in the EU-28. Journal of Cleaner Production, 191(1), 207-219. https://doi.org/10.1016/ j.jclepro.2018.03.220.

Rosenzweig, C., Solecki, W., Hammer, S. A., \& Mehrotra, S. (2010). Cities lead the way in climate-change action. Nature, 467(7318), 909-911.

SEAP-Padova. Sustainable Energy Action Plan - Piano di Azione per l'energia sostenibile del
Comune di Padova. (2011). , Accessed date: 10 May 2018 Available at: http:// mycovenant.eumayors.eu/docs/seap/264_218 1309421560.pdf.

Sims, R. E. H., Schock, R. N., Adegbululgbe, A., Fenhann, J., Konstantinaviciute, I., Moomaw, W., et al. (2007). Energy supply. In B. Metz, O. R. Davidson, P. R. Bosch, R. Dave, \& L. A. Meyer (Eds.). Climate Change 2007: Mitigation. Contribution of Working Group III to the Fourth Assessment Report of the Intergovernmental Panel on Climate ChangeCambridge, United Kingdom and New York, NY, USA: Cambridge University Presshttps://www.ipcc.ch/pdf/assessment-report/ar4/wg3/ar4-wg3-chapter4.pdf.

Van Staden, M., \& Musco, F. (2010). Local governments and climate change: Sustainable energy planning and implementation in small and medium sized communities. Berlin.

Zimmerman, R., \& Faris, C. (2011). Climate change mitigation and adaptation in North American cities. Current Opinion in Environment Sustainability, 3, 181-187. 